\title{
Mechanistic Investigations of Nickamine- catalyzed Hydrosilylation of Alkenes: Nickel Nanoparticles Are the Active Species
}

\author{
Marten L. Ploeger, Ivan Buslov, and Xile Hu*
}

\begin{abstract}
Hydrosilylation is an important chemical process for the synthesis of organosilanes and for the production of silicone polymers. The wide variety of catalysts developed for this reaction generally follow a Chalk-Harrod, or a sigma-bond metathesis mechanism. Recently, our group developed a nickel pincer complex, Nickamine, for highly selective hydrosilylation of alkenes. Preliminary mechanistic studies had suggested a pathway that deviates from both Chalk-Harrod and sigma-bond metathesis cycles. Here we used in situ NMR to monitor the hydrosilylation reaction. The observed induction period indicated that the species previously believed to be the resting state is merely a precatalyst. Via a combination of Transmission Electron Microscopy, mercury poisoning test, and competition reactions we show that the true catalyst is not a molecular nickel species, but rather nickel nanoparticles.
\end{abstract}

Keywords: Hydrosilylation $\cdot$ Mechanism $\cdot$ Nanoparticle $\cdot$ Nickel catalysis

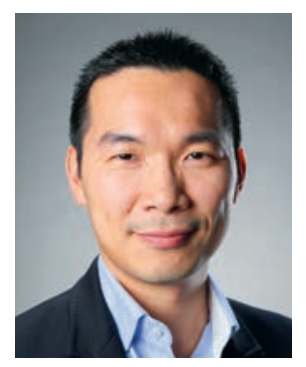

Xile $\mathbf{H u}$ was born in 1978 in Putian, Fijian Province, China. He received a B.S. degree from Peking University (2000) and a PhD degree from the University of California, San Diego (2004). He carried out a postdoctoral study at the California Institute of Technology before joining the faculty of the École Polytechnique Fédérale de Lausanne (EPFL) as a tenure-track assistant professor in 2007. He was promoted to associate professor in January 2013 and full professor in June 2016. He directs an interdisciplinary research program to develop catalysis for sustainable synthesis of added-value chemicals and for costeffective production of solar and electric fuels.

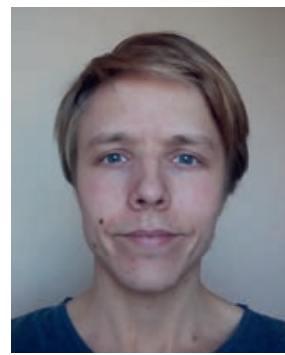

Marten Ploeger studied chemistry at the University of Amsterdam and the VU Amsterdam. During his Master's program, he conducted research in the group of Prof. Joost Reek in Amsterdam and in the group of Prof. Paul Pringle in Bristol. In 2016, he started his doctoral studies in the group of Prof. Xile $\mathrm{Hu}$ at EPFL in Lausanne, working on mechanistic analysis of nickel-catalyzed reactions.

\section{Introduction}

Hydrosilylation of unsaturated carbon-carbon bonds is an important industrial process for the synthesis of organosilanes, as well as for the production of silicone polymers. ${ }^{[1]}$ Typically, the reaction is catalyzed by platinum complexes, such as Speier's catalyst ${ }^{[2]}$ or Karstedt's catalyst. ${ }^{[3]}$ However, because of the scarcity of platinum, efforts have been made to develop hydrosilylation catalysts based on more abundant metals, ${ }^{[4,5]}$ including nickel.[6]
For platinum, the most widely accepted mechanism is the model proposed by Chalk and Harrod. ${ }^{[7,8]}$ It consists of oxidative addition of the hydrosilane, followed by hydride insertion into the alkene and reductive elimination of the product silane to close the catalytic cycle (Scheme 1A). For various catalysts, a modified Chalk-Harrod mechanism has been proposed, wherein silyl insertion occurs rather than hydride insertion, ${ }^{[9]}$ or a different resting state is observed..[10] Despite these small differences, these models still follow a general scheme of oxidative addition of the $\mathrm{H}-\mathrm{Si}$ bond and subsequent addition of the fragments to the alkene through insertion and reductive elimination.

A fundamentally different mechanism is often observed for early transition metals ${ }^{[11]}$ and rare earth metals, ${ }^{[12]}$ but also proposed for later transition metals. ${ }^{[13]}$ It consists of a metal hydride species that undergoes migratory insertion with the alkene. The resulting metal alkyl species then undergoes sigma-bond metathesis with the hydrosilane, releasing the product and regenerating the metal hydride (Scheme 1B).

Recently, different mechanisms have been proposed involving silyl radical formation and radical addition to the alkene. ${ }^{[14,15]}$ These findings indicate that the full scope of mechanistic possibilities for hydrosilylation is yet to be uncovered. Another potential blind spot in the mechanistic landscape could be metal-ligand cooperativity, which has been observed for $\mathrm{Si}-\mathrm{H}$ activation ${ }^{[16]}$ and in carbonyl hydrosilylation, ${ }^{[17,18]}$ but is not yet demonstrated for alkene hydrosilylation.

Recently, our group developed a hydrosilylation reaction of alkenes (1) and diphenylsilane (2a) with high regioselectivity to the anti-markovnikov product (3) using a nickel pincer complex (4, a methoxide derivative of the $\mathrm{Ni}-\mathrm{Cl}$ complex commonly called 'Nickamine') as catalyst (Scheme 2A). ${ }^{[19]}$ Preliminary mechanistic studies on this catalytic system led to the following key findings (reported in the doctoral thesis of Buslov). [20] i) As previously reported,[21] $\mathbf{4}$ is readily converted to $\mathbf{5}$ in the presence of 
Scheme 1. Common catalytic cycles for hydrosilylation. A: Chalk-Harrod. B: sigma bond metathesis.

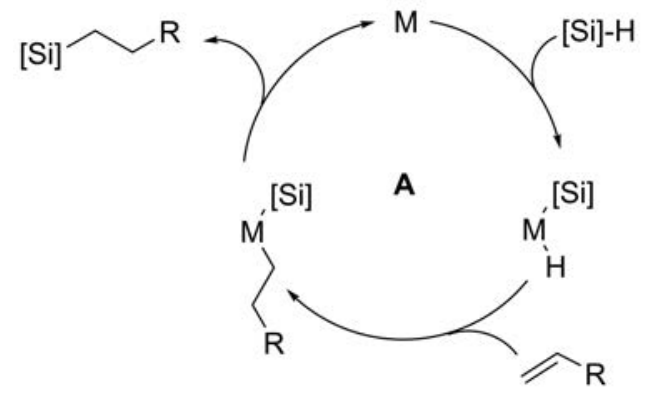

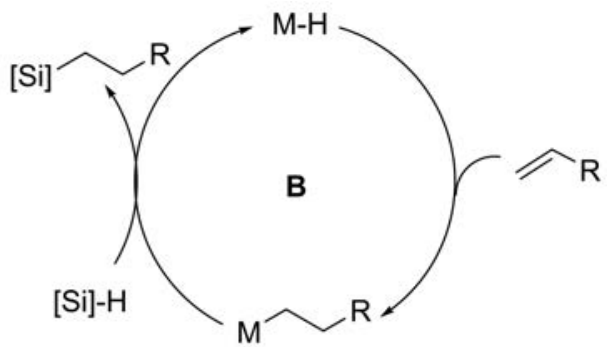

diphenylsilane, which in turn reacts rapidly with 1-octene (1a) to 6 (Scheme 2B). Under catalytic conditions, 5 is observed in the initial stages, but then decays over time, while $\mathbf{6}$ builds up initially and then reaches a plateau. ii) $\mathbf{6}$ can be used as catalyst in lieu of $\mathbf{4}$, with excellent yields (Scheme 2C), and $\mathbf{6}$ is still observable at the end of the reaction under these conditions. iii) A reaction between $\mathbf{6}$ and diphenylsilane yields only trace amounts of product over a duration twice as long as double the standard time for catalysis (Scheme 2D). iv) A stoichiometric reaction between 6, diphenylsilane and 1-decene (1b) forms diphenyldecylsilane (3b), without only traces of diphenyloctylsilane (3a) (Scheme 2E).

Combined, these findings point towards $\mathbf{6}$ as the resting state, but with the octyl group as a spectator ligand, rather than a reactive moiety that is converted into the product. This indicates a mechanism different from any Chalk-Harrod variations, or models containing sigma bond metathesis. Therefore, we performed a more indepth analysis of the hydrosilylation mechanism by $\mathbf{6}$, in search of an undiscovered mechanistic pathway for alkene hydrosilylation.

\section{Reaction Progress Monitoring by in situ ${ }^{1} \mathrm{H}$ NMR}

NMR is a useful technique for studying the course of a reaction in situ if both starting material and products can be quantified independently. Unfortunately, using diphenylsilane, the substrate of choice in our preliminary studies, led to overlapping peaks of the silane protons of the starting material and product, complicating their accurate quantification and kinetic analysis (Fig. S1A, Supplementary Information).

Therefore, we elected to study the hydrosilylation of 1-octene with phenylmethylsilane (2b) instead, using 1,3,5-trimethoxybenzene as internal standard. While the $\mathrm{Si}-\mathrm{H}$ signals of starting material and product still overlap, the $\mathrm{Si}-\mathrm{Me}$ hydrogen shifts are well-resolved
(Fig. S1B). The overalkylation byproduct can also be quantified. Moreover, despite the $1 \mathrm{~mol} \%$ loading, the catalyst can be readily quantified using the 12-proton signal of the dimethylamino moiety.

Fig. 1 shows the concentration of different species versus reaction time. Over the course of the NMR experiment, the yield of desired product phenylmethyloctylsilane (3c) is $84 \%$ based on converted 1-octene. By considering the overalkylated byproduct (3d), 92\% of the converted 1-octene can be accounted for. Various other products could be observed in GC-MS, but they could not be reliably quantified by NMR. Nonetheless, the vast majority of relevant species, including the catalyst, can be tracked, which allows for kinetic analysis of the reaction.

Interestingly, the reaction has an initial slow period of around 80 minutes, after which both the consumption of starting materials and the formation of product accelerate (Fig. 1). An induction period like this could be an indication of catalyst activation, ${ }^{[22]}$ autocatalysis, ${ }^{[23]}$ or a radical chain reaction with slow initiation. ${ }^{[24]}$

A radical chain reaction could be excluded by the hydrosilylation reaction of trans-(2-vinylcyclopropyl)benzene (1c). The reaction leads to the anti-markovnikov hydrosilylation product $\mathbf{3 e}$ with a $57 \%$ yield (Scheme 3 ). No ring opening product (3f) was observed, despite the high ring opening rate for a radical alpha to the cyclopropyl ring. ${ }^{[25]}$

A closer look at the concentration of $\mathbf{6}$ over time is given in Table 1 and Fig. S2A. The minimal difference in [6] at the beginning and end of the reaction explains why the decay had remained unnoticed in previous mechanistic studies. However, following the reaction over time reveals a small, but statistically significant downward slope. The decay rate follows the qualitative trend of conditions with double [phenylmethylsilane] > conditions with double [6] > conditions with double [1-octene] $>$ standard condi-
Scheme 2. Results of preliminary mechanistic experiments.
A

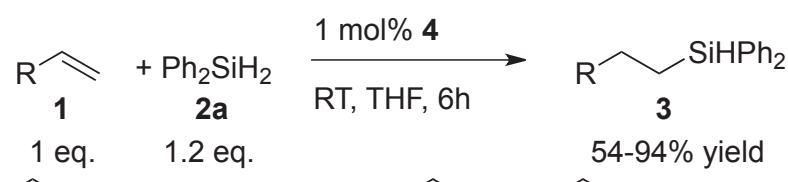

B

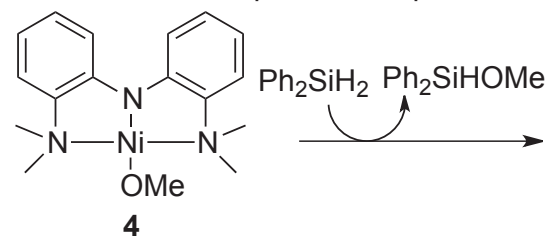<smiles>CN1N2c3ccccc3N(C)C(C)(c3ccccc32)N1C</smiles><smiles>C=CCCCCCC</smiles><smiles>CC[N+]12N(C)c3ccccc3N(c3ccccc3N1C)N2C</smiles>
6<smiles></smiles>

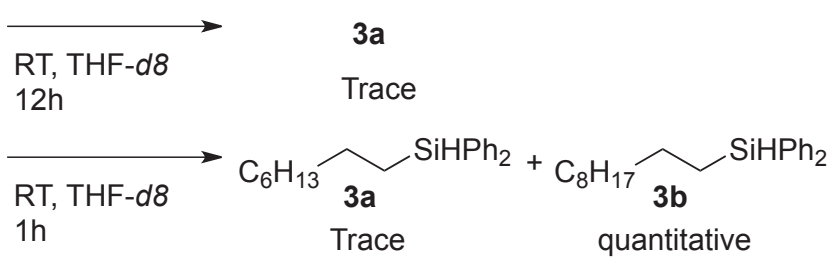




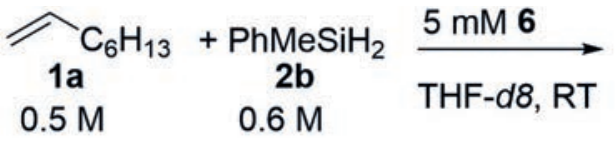

$\mathrm{PhMeSiHOct}+\mathrm{PhMeSi}(\mathrm{Oct})_{2}$ 3c

3d

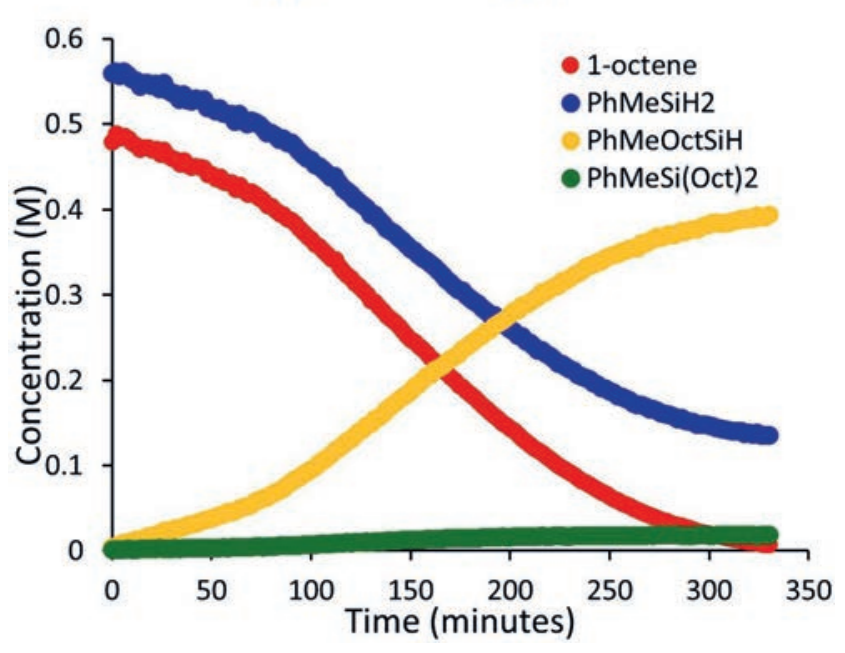

Fig. 1. Concentration of starting materials and products over time. from the catalyst is difficult to determine. One possibility would be the formation of nickel particles. This is not unprecedented for this type of complexes, since it is known to occur for 5. ${ }^{[20,21]}$ Indeed, particles could be observed with Transmission Electron Microscopy in samples prepared at the end of a catalytic run (Fig. S3). However, the mere observation of particles does not inform whether these are active catalysts, or merely inactive decomposition products.

\subsection{Mercury Test}

A hydrosilylation reaction in the presence of 1600 equivalents of mercury with respect to total nickel concentration gave an NMR yield of only $1.5 \%$ over 6 hours. 6 was still present at a concentration approximately $90 \%$ of the starting concentration. Moreover, the color of the THF solution at the end of the reaction was the same dark red color as $\mathbf{6}$, whereas reaction mixtures in absence of mercury turn brown over time. The observations support the hypothesis that 6 is partially transformed to nickel particles, which are responsible for catalysis and the color change. When the mercury droplets sequester these particles, catalysis is inhibited and the color remains red.

The observed inhibition by $\mathrm{Hg}$ is contradictory to our previously reported results: we reported the same yield in absence of $\mathrm{Hg}$ and in presence of 100 equivalents of $\mathrm{Hg}$ with respect to total nickel concentration. ${ }^{[20]}$ One explanation for this would be that the mercury test is sensitive to both the $\mathrm{Hg}$ to catalyst ratio and the stirring rate. ${ }^{[26]} 100$ Equivalents of $\mathrm{Hg}$ could therefore simply not be enough to observe the sequestration effect, leading to a false negative.
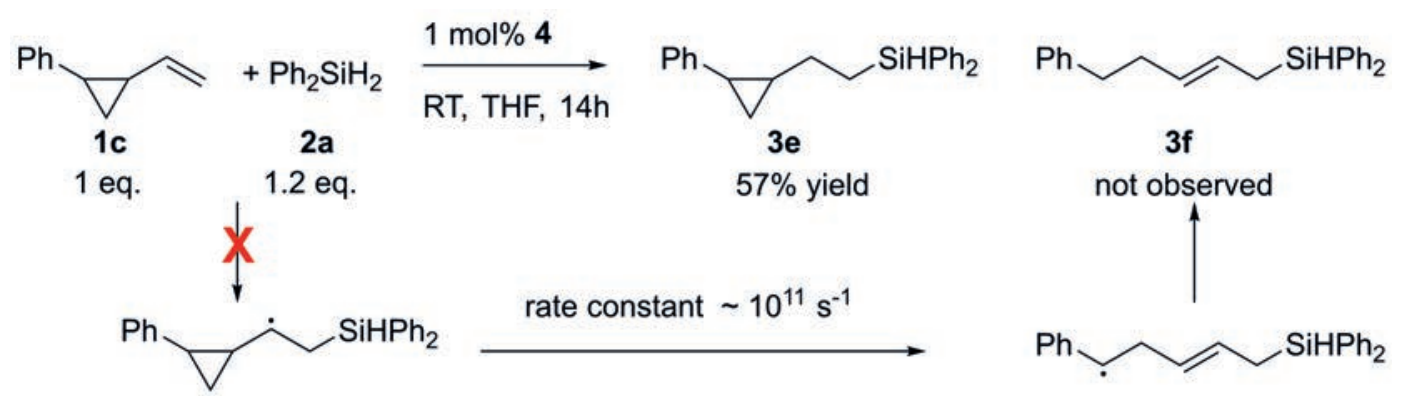

Scheme 3. Hydrosilylation reaction of 1c along with the pathway and product that would be expected if a radical chain reaction was operative.

tions. Interestingly, this is the inverse of a qualitative trend in the length of induction period for the hydrosilylation reaction under these conditions (conditions with double [phenylmethylsilane] $<$ conditions with double $[6]<$ conditions with double [1-octene] $\approx$ standard conditions, Fig. S2B). These data indicate that the decay of $\mathbf{6}$ is an activation pathway towards the true catalyst.

\section{Determination of True Catalyst}

Due to the low concentration of the catalyst and the minimal conversion of it during catalysis, the identity of the decay product

Table 1. Fate of [6] during catalysis

\section{Deviation \\ from standard conditions $^{\mathbf{a}}$}

\begin{tabular}{|l|c|c|c|}
\hline None & $94 \%$ & $-6.8(1) * 10^{-7}$ & 0.955 \\
\hline Double [1-octene $]_{0}$ & $95 \%$ & $-7.8(2) * 10^{-7}$ & 0.891 \\
\hline Double $[\mathrm{PhMeSiH} 2]_{0}$ & $80 \%$ & $-2.78(3) * 10^{-6}$ & 0.912 \\
\hline Double [1-octyl] & $93 \%$ & $-2.35(3) * 10^{-6}$ & 0.980 \\
\hline
\end{tabular}

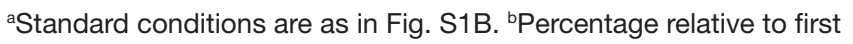
measured concentration. 'Decay of [6] modelled linearly. Value in parentheses denotes the standard error of the slope.

\section{Linear regression ${ }^{c}$}

Slope $\quad \mathbf{R}^{2}$

$\left(\mathrm{M}\right.$ min $\left.^{-1}\right)$

0.955

0.891

912

980

.

On the other hand, the mercury test can also lead to false positives, as certain metal complexes are known to react directly with mercury. ${ }^{[26-28]}$ Although 6 itself does not react with mercury to a significant extent, as $90 \%$ of it is still remaining after 6 hours reaction time with 1600 equivalents of $\mathrm{Hg}$, it is possible that its unidentified decomposition product is a mercury-sensitive nickel complex. In addition, there is the possibility of equilibration between molecular catalytic nickel species and inactive nickel clusters ${ }^{[29]}$ at a higher rate than catalysis. Under such circumstances, even if the catalytic metal complex is itself inert to mercury, sequestration of the clusters by $\mathrm{Hg}$ still leads to a decrease of the complex concentration via Le Chatelier's principle. Both false positive inhibition pathways (via mercury-sensitivity and via depletion of species connected to the active catalyst through equilibration) should be sensitive to the amount of mercury added, which would explain why such a false positive would only be observed under the conditions presented here and not under the conditions we reported earlier.

\subsection{Competition Experiments}

To better differentiate between catalysis by nickel particles and catalysis by a heretofore unidentified nickel complex derived from 6, substrate competition experiments were performed. This tool has already proven useful to differentiate molecular catalysis from cluster catalysis for reactions catalyzed by palladium. ${ }^{[30]}$ In principle, when two substrates compete for reactivity with the same catalytic species, the outcome should be dependent on the respective rate constants and the concentrations of different 
substrates, but not on the concentration of the catalytic species. However, agglomeration rates change non-linearly with the concentration of available metal atoms. ${ }^{[31-33]}$ Therefore, the shape and size of particulate nickel should change with total nickel concentration (or factors influencing reduction of precursors to $\mathrm{Ni}(0)$ ). Different sizes and shapes of particles lead to different reactivity and therefore could lead to a different selectivity pattern in competition experiments. Thus, the selectivity between two substrates should be unaffected by concentration for molecular catalysis, but may change for particulate catalysis.

Fig. 2 shows a plot of conversion of 1 -octene versus the conversion of $\mathrm{N}$-allylcarbazole (1d) at different concentrations of nickel. A plot like this allows for a direct visual comparison of catalyst selectivity under different conditions. From the graph it is clear that the selectivity changes as the nickel concentration is increased from $3.5 \mathrm{mM}$ to $17.5 \mathrm{mM}(0.7-3.5 \mathrm{~mol} \%$ with respect to total alkene concentration). The difference between the conditions is especially noticeable at a high alkene conversion. The difference between conditions is also larger than the difference between two runs under the same conditions. At the even higher concentration of $35 \mathrm{mM}(7 \mathrm{~mol} \%)$, the error becomes too large to clearly differentiate between this concentration and $17.5 \mathrm{mM}$. Nonetheless, the difference in selectivity between conditions closest to those applied in standard catalysis ( $1 \mathrm{~mol} \% \mathrm{Ni})$ supports the hypothesis of particulate nickel being responsible for catalysis.

\section{Mechanism of Decomposition of 6}

Two possible pathways for the decomposition of $\mathbf{6}$ may be considered. On the one hand, it is possible that beta-hydride elimination occurs, releasing 1-octene and generating 5 (Scheme 4A). Although this is an uphill process, it has been indirectly demonstrated to occur through isomerization reactions. ${ }^{[34]}$ Complex $\mathbf{5}$ is known to decompose to nickel particles and free ligand (7) either by itself,[21] or in presence of a silane. ${ }^{[20]}$ Alternatively, 6 may react with the silane directly (Scheme 4B). Following reductive elimination of the alkylsilane, $\mathrm{Ni}(0)$ can release the ligand and agglomerate. Both pathways can account for the results of hydrosilylation of 1-decene with stoichiometric 6 (Scheme 2E): there is either just a small amount of 1-octene generated during catalyst activation to compete with 1-decene (Scheme 4A), or only a small amount of octylsilane is generated before enough active catalyst is generated to consume all silanes with 1-decene (Scheme 4B).

To probe the mechanism of decomposition of the catalyst precursor, its decomposition was monitored by NMR. Since the decomposition is too slow under standard conditions (see Table 1 and Fig. S2A) for extraction of kinetic parameters from the decay trace, these studies were performed at $40{ }^{\circ} \mathrm{C}$.

Under these conditions, 6 still decomposes slowly by itself (Fig. 3A, black trace). However, in presence of phenylmethylsilane, the decomposition speeds up considerably. Fig. 3B shows the natural logarithm of [6] decreases linearly in time with all the tested concentrations of phenylmethylsilane, indicating a pseudo-first or-
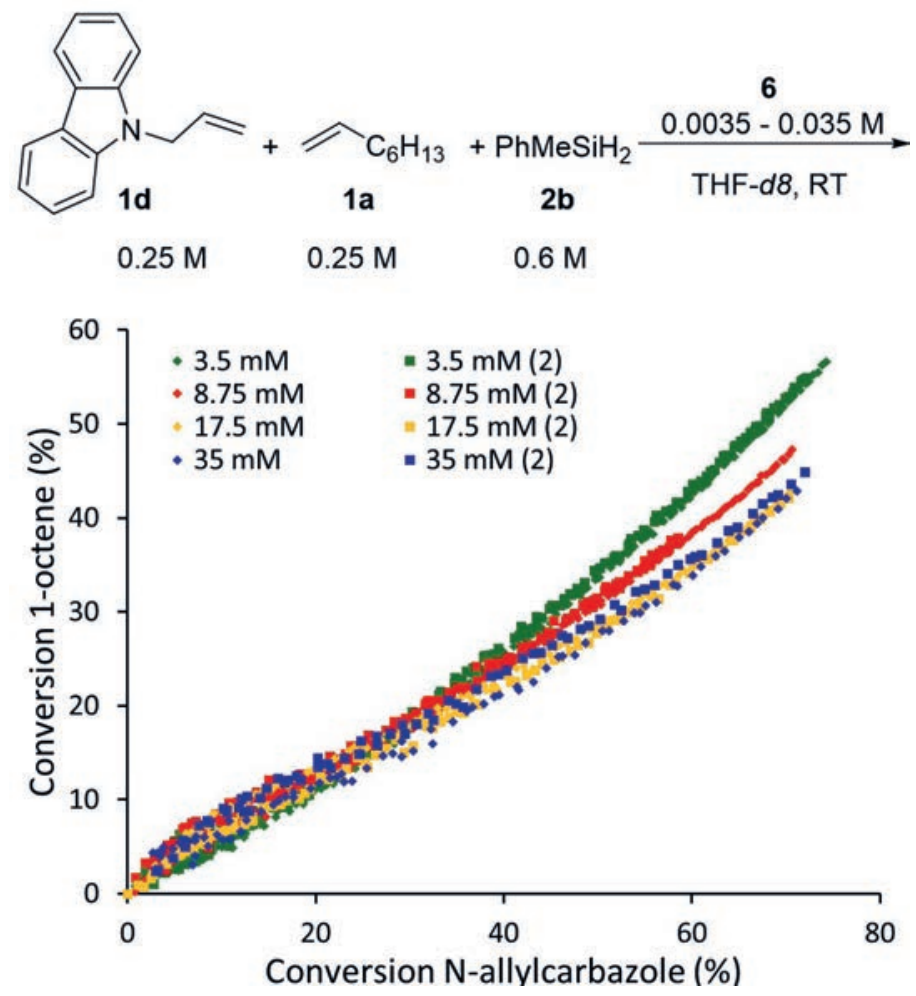

Fig. 2. Competition experiments between $\mathrm{N}$-allylcarbazole (1d) and 1-octene (1a) at different concentrations of catalyst precursor 6 . Conversions determined by NMR. Two runs (diamonds and squares) of each condition are plotted to show the good agreement between them.

der reaction. The observed rate constant for this reaction shows a linear relation with the concentration of silane (Figure 3C). Finally, when a hydrosilylation reaction of 1-octene was set up at $40{ }^{\circ} \mathrm{C}$ with excess phenylmethylsilane, there is no difference in decay rate of 6 in presence or absence of 1-octene (Figure 3D). Moreover, the concentration of $\mathbf{6}$ shows a linear relation with $f(t)$ (Eqn. (1)).

$$
f(t)=\sum_{\mathrm{i}=1}^{\mathrm{n}}\left(\frac{[6]_{\mathrm{i}}+[6]_{\mathrm{i}-1}}{2}\right)^{1}\left(\frac{[2 \mathbf{b}]_{\mathrm{i}}+[2 \mathbf{b}]_{\mathrm{i}-1}}{2}\right)^{1}\left(\mathrm{t}_{\mathrm{i}}-\mathrm{t}_{\mathrm{i}-1}\right)
$$

This linearity indicates all variables that influence the decay rate of $\mathbf{6}$ are included in $f(t) .{ }^{[35]}$ Thus, with the data from Fig. 3 a rate law for the decomposition of $\mathbf{6}$ can be formulated (Eqn. (2)). This rate law is incompatible with Scheme 4A, since that should lead to Eqn. (3), or either of its simplifications, Eqns (4) or (5), none of which is equivalent to Eqn. (2). Conversely, the rate law of Eqn. (2) fits Scheme 4B, provided the silane addition to 6 is the rate-determining step. Therefore, we propose the mechanism depicted in Scheme 4B for decomposition of $\mathbf{6}$, although the exact nature of intermediate $\mathbf{8}$ may well be different.
Scheme 4. Potential pathways for decomposition of 6 .
A

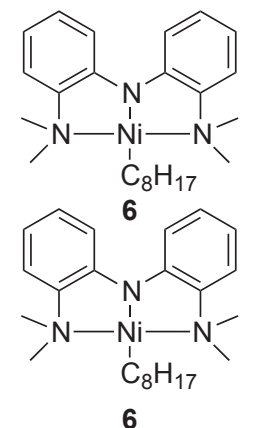<smiles>C=CC(C)C(C)(C)C(=O)c1ccccc1</smiles>

\section{[Si]H}

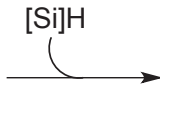<smiles>CN1Cn2c3ccccc3n(C)n1n2-c1ccccc1</smiles>

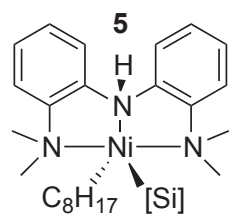
8
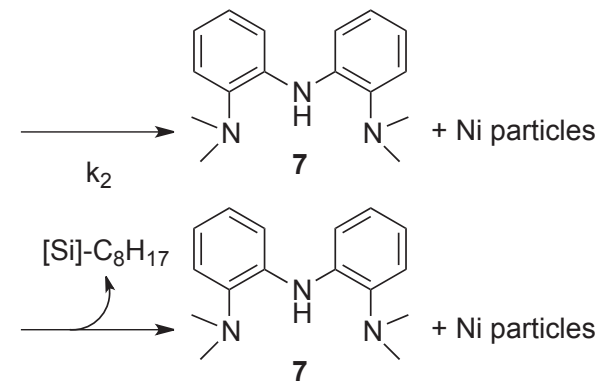
$\frac{-\mathrm{d}[\mathbf{6}]}{\mathrm{dt}}=\mathrm{k}_{o b s}[\mathbf{6}][2 \mathrm{~b}]$

$\frac{-d[6]}{d t}=\frac{\mathrm{k}_{1} \mathrm{k}_{2}[6][2 \mathbf{b}]}{\mathrm{k}_{-1}[\mathbf{1 a}]+\mathrm{k}_{2}[2 \mathbf{b}]}$

$\frac{-\mathrm{d}[\mathbf{6}]}{\mathrm{dt}}=\mathrm{K}_{1} \frac{\mathrm{k}_{2}[\mathbf{6}][\mathbf{2 b}]}{[\mathbf{1} \mathbf{a}]} \quad\left(\mathrm{k}_{2}[\mathbf{2} \mathbf{b}] \ll \mathrm{k}_{-1}[\mathbf{1} \mathbf{a}]\right)$

$\frac{-\mathrm{d}[6]}{\mathrm{dt}}=\mathrm{k}_{1}[6]$

$\left(\mathrm{k}_{2}[\mathbf{2 b}] \gg \mathrm{k}_{-1}[\mathbf{1 a}]\right)$

\section{Conclusions}

Through a detailed mechanistic study, we have revealed that a hydrosilylation reaction, previously believed to occur with a molecular nickel catalyst, is in reality catalyzed by nickel nanoparticles. In addition, we propose a mechanism for the conversion of the pre-catalyst to nickel( 0$)$ that is consistent with both our results and previously reported experiments.

The results presented in this study underline the importance of thorough mechanistic research, since changes in the nature of the catalytic species can be subtle and may be easily missed with superficial mechanistic probes.

\section{Acknowledgements}

This work is funded by the European Union's Horizon 2020 research and innovation programme under the Marie Curie Skłodowska-Curie grant agreement. Project ID: 675020. Project name: Non-Noble Metal Catalysis - NoNoMeCat. We thank Lichen Bai for assistance with TEM measurements.

\section{Supplementary Information}

Supplementary information is available on https://www.ingentaconnect.com/content/scs/chimia

Received: April 8, 2020

[1] D. Troegel, J. Stohrer, Coord. Chem. Rev. 2011, 255, 1440, https://doi. org/10.1016/j.ccr.2010.12.025.

[2] J. L. Speier, J. A. Webster, G. H. Barnes, J. Am. Chem. Soc. 1957, 79, 974, https://doi.org/10.1021/ja01561a054.

[3] B. D. Karstedt, General Electric Company, US3775452A, 1973

[4] J. V. Obligacion, P. J. Chirik, Nat. Rev. Chem. 2018, 2, 15; https://doi. org/10.1038/s41570-018-0001-2.

[5] X. Du, Z. Huang, ACS Catal. 2017, 7, 1227, https://doi.org/10.1021/ acscatal.6b02990.

[6] Y. Nakajima, K. Sato, S. Shimada, Chem. Rec. 2016, 16, 2379, https://doi. org/10.1002/tcr.201600056.
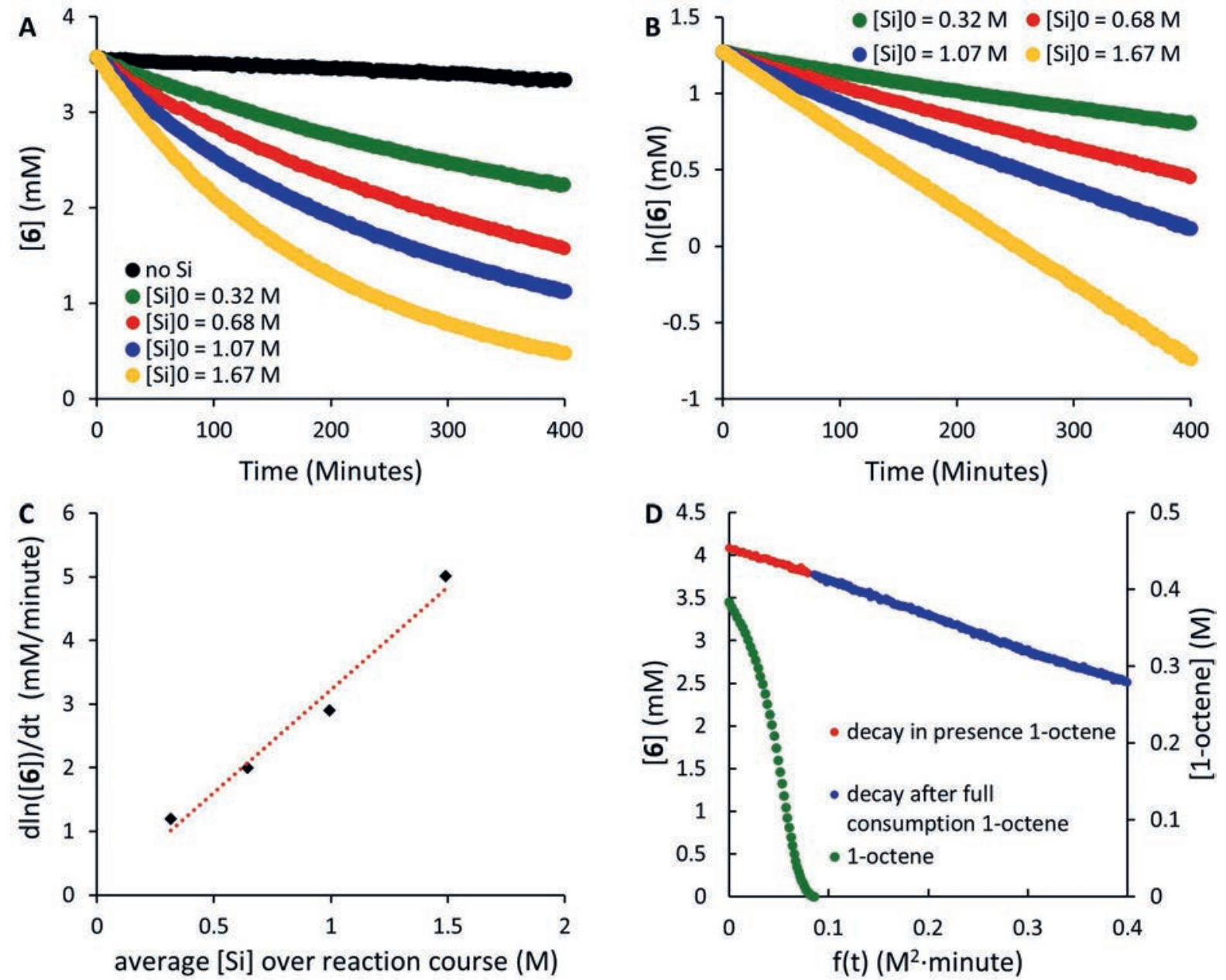

Fig. 3. Decay of [6] at $40{ }^{\circ} \mathrm{C}$ in THF-d8 followed by ${ }^{1} \mathrm{H}$ NMR. Si means $\mathrm{PhMeSiH}_{2}$. (A) Concentration of 6 versus time with various amounts of starting concentration of silane. (B) Same data of A, but $\ln ([6])$ now plotted to demonstrate first order in nickel. (C) Slopes of the traces in $B$ plotted against the silane concentration to demonstrate first order in silane. The average concentration over time of the silane is taken, as a slight decrease in concentration is observed during the reaction. (D) Hydrosilylation reaction of 1 -octene with excess $\mathrm{PhMeSiH}_{2}$ followed by ${ }^{1} \mathrm{H}$ NMR. [6] is plotted on the left $y$-axis, while [1-octene] is plotted on the right $y$-axis. The $x$-axis is Eqn. (1). 
[7] A. J. Chalk, J. F. Harrod, J. Am. Chem. Soc. 1965, 87, 16, https://doi. org/10.1021/ja01079a004.

[8] T. K. Meister, K. Riener, P. Gigler, J. Stohrer, W. A. Herrmann, F. E. Kühn, ACS Catal. 2016, 6, 1274, https://doi.org/10.1021/acscatal.5b02624.

[9] M. A. Schroeder, M. S. Wrighton, J. Organomet. Chem. 1977, 128, 345, https://doi.org/10.1016/S0022-328X(00)92207-1.

[10] S. B. Duckett, R. N. Perutz, Organometallics 1992, 11, 90, https://doi. org/10.1021/om00037a022.

[11] L. Jia, J. Zhao, E. Ding, W. W. Brennessel, J. Chem. Soc., Dalton Trans. 2002, 13, 2608, https://doi.org/10.1039/b200789d

[12] P.-F. Fu, L. Brard, Y. Li, T. J. Marks, J. Am. Chem. Soc. 1995, 117, 7157, https://doi.org/10.1021/ja00132a015.

[13] M. Brookhart, B. E. Grant, J. Am. Chem. Soc. 1993, 115, 2151, https://doi. org/10.1021/ja00059a008.

[14] G. Vijaykumar, A. Pariyar, J. Ahmed, B. K. Shaw, D. Adhikari, S. K. Mandal, Chem. Sci. 2018, 9, 2817, https://doi.org/10.1039/C7SC04687A

[15] R. Zhou, Y. Y. Goh, H. Liu, H. Tao, L. Li, J. Wu, Angew. Chem. Int. Ed. 2017, 56, 16621, https://doi.org/10.1002/anie.201711250.

[16] T. Higashi, S. Kusumoto, K. Nozaki, Chem. Rev. 2019, 119, 10393, https:// doi.org/10.1021/acs.chemrev.9b00262.

[17] K. D. Hesp, R. McDonald, M. J. Ferguson, M. Stradiotto, J. Am. Chem. Soc. 2008, 130, 16394, https://doi.org/10.1021/ja8062277.

[18] J. Fuchs, E. Irran, P. Hrobárik, H. F. T. Klare, M. Oestreich, J. Am. Chem. Soc. 2019, 141, 18845, https://doi.org/10.1021/jacs.9b10304

[19] I. Buslov, J. Becouse, S. Mazza, M. Montandon-Clerc, X. Hu, Angew. Chem Int. Ed. 2015, 54, 14523, https://doi.org/10.1002/anie.201507829.

[20] I. Buslov, 'Chapter 2: Chemoselective Alkene Hydrosilylation Catalyzed by Nickel Pincer Complexes', in 'Nickel-Catalyzed Hydrosilylation of Alkenes and Transition-Metal-Free Intermolecular alpha-C-H Amination of Ethers', École Polytechnique Fédérale de Lausanne, 2016, pp 47-80.

[21] J. Breitenfeld, R. Scopelliti, X. Hu, Organometallics 2012, 31, 2128, https:// doi.org/10.1021/om201279j.

[22] A. Martínez-Carrión, M. G. Howlett, C. Alamillo-Ferrer, A. D. Clayton, R. A. Bourne, A. Codina, A. Vidal-Ferran, R. W. Adams, J. Burés, Angew. Chem. Int. Ed. 2019, 58, 10189, https://doi.org/10.1002/anie.201903878.

[23] M. Sankaralingam, Y.-M. Lee, W. Nam, S. Fukuzumi, Inorg. Chem. 2017, 56, 5096, https://doi.org/10.1021/acs.inorgchem.7b00220.

[24] K. W. E. Sy Piecco, A. M. Aboelenen, J. R. Pyle, J. R. Vicente, D. Gautam, J. Chen, ACS Omega 2018, 3, 14327, https://doi.org/10.1021/ acsomega. $8 \mathrm{~b} 01725$.

[25] M. Newcomb, C. C. Johnson, M. B. Manek, T. R. Varick, J. Am. Chem. Soc. 1992, 114, 10915, https://doi.org/10.1021/ja00053a031.
[26] V. M. Chernyshev, A. V. Astakhov, I. E. Chikunov, R. V. Tyurin, D. B. Eremin, G. S. Ranny, V. N. Khrustalev, V. P. Ananikov, ACS Catal. 2019, 9 , 2984, https://doi.org/10.1021/acscatal.8b03683.

[27] O. N. Gorunova, I. M. Novitskiy, Y. K. Grishin, I. P. Gloriozov, V. A. Roznyatovsky, V. N. Khrustalev, K. A. Kochetkov, V. V. Dunina, Organometallics 2018, 37, 2842, https://doi.org/10.1021/acs. organomet.8b00363.

[28] K. Ehara, K. Kumagaya, Y. Yamamoto, K. Takahashi, H. Yamazaki, J. Organomet. Chem. 1991, 410, C49, https://doi.org/10.1016/0022328X(91)83017-X

[29] D. B. Eremin, V. P. Ananikov, Coord. Chem. Rev. 2017, 346, 2, https://doi. org/10.1016/j.ccr.2016.12.021.

[30] A. F. Schmidt, A. A. Kurokhtina, E. V. Larina, Catal. Sci. Technol. 2014, 4, 3439, https://doi.org/10.1039/C4CY00479E.

[31] K. X. Bhattacharyya, C. Pradel, P. Lecante, N. Mézailles, Chem. Eur. J. 2017, 23, 9352, https://doi.org/10.1002/chem.201701258.

[32] A. F. Schmidt, A. Al-Halaiqa, V. V. Smirnov, J. Mol. Catal. A: Chem. 2006, 250, 131, https://doi.org/10.1016/j.molcata.2006.01.051.

[33] J. D. Aiken, R. G. Finke, J. Am. Chem. Soc. 1998, 120, 9545, https://doi. org/10.1021/ja9719485.

[34] J. Breitenfeld, O. Vechorkin, C. Corminboeuf, R. Scopelliti, X. Hu, Organometallics 2010, 29, 3686, https://doi.org/10.1021/om1007506.

[35] J. Burés, Angew. Chem. Int. Ed. 2016, 55, 16084, https://doi.org/10.1002/ anie. 201609757.

[36] I. Buslov, F. Song, X. Hu, Angew. Chem. Int. Ed. 2016, 55, 12295, https:// doi.org/10.1002/anie.201606832.

[37] T. Galeandro-Diamant, I. Suleimanov, L. Veyre, M. Bousquié, V. Meille, C. Thieuleux, Catal. Sci. Technol. 2019, 9, 1555, https://doi.org/10.1039/ C8CY01487F.

\section{License and Terms}

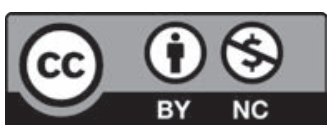

This is an Open Access article under the terms of the Creative Commons Attribution License CC BY_NC 4.0. The material may not be used for commercial purposes.

The license is subject to the CHIMIA terms and conditions: (http:// chimia.ch/component/sppagebuilder/?view=page \&id=12).

The definitive version of this article is the electronic one that can be found at doi:10.2533/chimia.2020.444 